\title{
TEN YEARS OF LIQUID DEMOCRACY RESEARCH AN OVERVIEW
}

\author{
Alois Paulin ${ }^{1}$
}

DOI: $10.24989 /$ ocg.338.36

\begin{abstract}
Ten years have passed since in 2009 two independent technical systems pioneered liquid democracy (LD): Župa, a system developed for the Student Organisation of FIS in Slovenia, followed closely by LiquidFeedback, which served the Pirate Party in Berlin, Germany. First academic papers appeared in 2010 targeting the e-democracy research community, and later followed by researchers from artificial intelligence. This paper provides an overview of the scholarly discussions that developed in the past decade, and the technical implementations and initiatives that emerged.
\end{abstract}

\section{Introduction}

Liquid democracy (LD) is a way of making collective decisions, which does not depend on electing representatives. Instead, each member of a group can delegate its power including all power delegated to them to another member and withdraw it again at any time.

Paulin [35, 39] explains LD by following example: "Let us assume a group of six members - Ann, Bob, Carl, Dan, Eve, and Franck. Let us further assume that each member of the group has an equal share in making a common decision: hence, each has one vote of equal value. Ann has delegated her power to Bob, Bob and Carl to Dan, and Dan to Eve; Franck has not delegated his vote to anyone. Given these delegations, the distribution of power in the group would be as follows: Eve would hold $5 / 6$ votes (hers + Dan's + the delegations Dan received from Bob and Carl + the delegation Bob received from Ann), and Franck would hold 1/6 of all votes. This distribution could change any moment: If Bob would delegate his power to Franck, then Franck would hold 3/6 of all votes (his own + Bob's + the power Ann delegated to Bob), and Eve the remaining 3/6."

Blum \& Zuber [4] attempted to define LD as a model: "All members of a political community that satisfy a set of reasonable participatory criteria (adulthood, baseline rationality) are entitled to: (I) directly vote on all policy issues (direct democratic component); (II) delegate their votes to a representative to vote on their behalf on (1) a singular policy issue, or (2) all policy issues in one or more policy areas, or (3) all policy issues in all policy areas (flexible delegation component); (III) delegate those votes they have received via delegation to another representative (meta-delegation component); (IV) terminate the delegation of their votes at any time (instant recall component)."

This liquidity of fluctuation of power, which is a combination of Blum \& Zuber's flexible delegation component, meta-delegation component, and instant recall component is what gives LD its name.

The liquidity of LD is something that cannot be achieved in no other way than by means of information technology (IT) solutions that store and manage the network that represents the relations

\footnotetext{
${ }^{1}$ Siemens, Smart Infrastructure, Siemensstr. 90,1210 Wien, alois@apaulin.com
} 
between the members of the group. First such known solutions appeared around $2007-2009$. The first system known to provide LD capabilities was Michael Allen's Votorola [51]. The first technical LD system that was made available to a concrete organisation was Paulin's Župa [41, 42], which brought LD to the Student Union of the Faculty of Information Studies in Novo mesto. Slightly later LiquidFeedback [2, 46] was released for use by the German Pirate Party. Several other LD initiatives emerged independently in the years that followed, such as Civicracy [21], GoogleVotes [22], or Sovereign [45].

Scholarly activities emerged, which discussed the pros and cons of LD [4], or sought for new domains to which LD could be applied, such as public governance [39], music recommendation [6], public financing [38], or blockchain [18]. Furthermore, the artificial intelligence scholarly community became interested in utilizing LD, which resulted in a separate stream of research $[12,13,20,25]$.

This paper aims to sum up the decade that followed the pioneering applications of LD. Section 2 aims to give an overview of the known technical systems developed so far. In section 3 we shall discuss the different perspectives on LD taken by the involved researchers and LD enthusiasts. A summary of the findings shall be provided in section 4.

\section{Known initiatives and systems}

Some early e-participation systems designed for LD have been documented by Thomas von der Elbe [17], who identified two systems that feature both delegation of power to proxies as required for delegated voting, as well as the spontaneous withdrawal of delegated power, which is crucial for the characteristic liquidity of LD. These two systems were Votorola and LiquidFeedback.

Von der Elbe's [17] comparison of then-available systems is focused on systems for e-participation. To compare the systems, he devised a set of ten criteria as follows:

1. Can the voters vote on any local, national and global topic that concerns them?

2. Can the voters vote at any time - i.e. $24 / 7$ ?

3. Can the voters put their own proposals to vote?

4. Can the voters delegate their voting power, and all received delegations to others?

5. Can the voters change their vote or opinion?

6. Can the voters choose between different voting tools and have their opinion / vote be presented in all other tools as well?

7. Can the voters filter votes, by e.g. nationality, age, etc.?

8. Can the voters verify the results of a vote?

9. Can some voters maintain their own voting tool that would be independent from governments or institutions, but would still be connected to other voters?

10. Maturity of development.

By von der Elbe's comparison criteria, a system can be considered to enable LD if it scores in the criteria 4 (transient delegation of power) and 5 (ability to change opinion / vote - i.e., "liquidity"). Also Blum \& Zuber [4], independently, defined criteria for LD that overlap with those by von der Elbe: according to their definition LD is characterized by direct democracy, flexible delegation (equals von der Elbe's crit. 4), meta-delegation, and instant recall (von der Elbe's crit. 5).

According to von der Elbe, Votorola reached full score in both criteria 4 and 5. LiquidFeedback received full score for criteria 4 (transient delegations) and only $3 / 10$ for criteria 5 (liquidity). A third 
system, Adhocracy, scored fully for delegations, but failed to exhibit liquidity. As the other criteria are targeting e-participation systems, they are of no relevance to LD systems in general.

Other LD systems have been mentioned by Paulin [35], who lists six LD instantiations known by 2016: Župa, LiquidFeedback, Civicracy, Polly, democratia2.ru, and GoogleVotes. In 2017 a new system, Sovereign, appeared.

For some of these and other systems no documentation can be found in support of their categorization as systems that would enable LD. Polly [16] for example, is associated with LD only by a brief mentioning on their Github page, with no further justification as to whether or not Polly would indeed offer both delegated voting as well as the required liquidity. Also for democratia2.ru, which is being considered as a variation of LD by Velikanov [48], no source can be found that would justify its categorization as a LD system.

Another system that is often associated with LD is Adhocracy. The reason why it is associated with LD is that the organisation that developed it is called Liquid Democracy e.V. However, Adhocracy has been identified by von der Elbe [17] as a system that is capable only of delegated voting without the liquidity necessary to qualify as a system for LD. Further confusion is added by scholarly publications such as the one by Harraß [23], whose title implies that LD was being used in an eparticipation pilot of the German Bundestag's (parliament) Commission of Enquiry "The Internet and the Digital Society". Also Ramos [43] implies LD being used in this e-participation pilot making use of Adhocracy. Said e-participation pilot however merely involved the partnership of Liquid Democracy e.V., which provided a modified version of Adhocracy that attracted about 3.250 users to participate in online deliberations on the theme at stake [19]. Despite an abundance of publications, neither use of transitive vote delegation, nor the use of any "liquid" features are reported.

Several peer-reviewed scholarly publications falsely claim that further organisations have made use of LD. Thus, Christoff \& Grossi [12] mention the former Swedish political party Demoex having used LD, which is wrong. Demoex was merely a so-called proxy party [7], which aimed to score by giving their party base direct-democratic access to define how Demoex's representatives (if any) would have voted in city council or parliament. They also mention the US campaign Make Your Laws, but also for that no indication exists that they would have made use of LD. According to the description of the principles of Make Your Laws [32] the idea was likewise that of establishing a proxy party.

Claims of LD being used or intended to be used are occasionally made by organisations and individuals from politics. Such claims mushroom in form of news articles, blog posts or similar. Thus for example, according to the online magazine TechCrunch [28], the Australian political party Flux Party aimed for providing LD in 2016 (but apparently failed), and so did David Ernst, a political candidate in California who aimed to score by promising LD, but apparently failed as well.

False credit on the use of LD is also given to the European research project WeGovNow [5], for which e.g. Bloembergen \&al. [3] or Brill [8] imply that it had used LD. Alas, when studying the deliverables of the project, one finds that all that has been done in the project was to integrate LiquidFeedback into a WeGovNow platform prototype [1]. No evidence of any conducted pilots that would have made use of LD or at least delegated voting has been published, nor is obtainable on request [40]. 
This section aims to provide a comprehensive overview of the known LD systems considering the available knowledge on their features, status, and fate. As of 2020, the known systems for which enough evidence exists that they implemented both transient power delegation as well as liquidity of power delegation are: Votorola, Župa, LiquidFeedback, Google Votes, Civicracy, and Sovereign.

\subsection{Votorola}

The earliest known project to design a system for LD is Votorola, which Michael Allan began developing in 2007 [51, 52], later joined by Thomas von der Elbe and Christian Weilbach [14]. Votorola remained under experimental development until 2014 [50] and reached alpha-level maturity. The German Pirate Party considered Votorola as a tool for their inner-party decision-making procedures [29], but did not decide to use it in the end. No applied use of Votorola has been documented.

\section{2. Župa}

Župa has been developed by Alois Paulin between 2008-2009 and is the first LD system that has been adopted for use by a real-world organisation, the Student Union of the Faculty of Information Studies in Novo mesto - Š OFIŠ [41, 42]. ŠOFIŠ was established in 2010 with Župa being an integral part of the organisation's statute.

In Župa, power could be transiently delegated to others in the community and withdrawn at any time. Digitally signed proposals to the community (for, e.g. funding of projects) were published anywhere on the WWW in form of meta data stored in a Web page (HTML document), which were detected and visualized by a browser plug-in. Votes on these proposals could be published publicly online in form of meta data stored in any HTML document or cast anonymously. Web crawlers would crawl the WWW to extract this meta data, and thus gather information on published proposals and public votes. The Web crawlers would make this information available on a central Web page. Once a proposal would have gathered support beyond a certain threshold (e.g. the support of $51 \%$ or $75 \%$ of all members of the community), the proposal could be enacted.

Župa however never reached past the stage of a proof-of-concept (TRL 3-4), as ŠOFIŠ failed to commit to using LD even before Župa could be tested in a real environment [35].

\subsection{LiquidFeedback (LQFB)}

The German Pirate Party used LD through their system LQFB [2] during the period of May 2010 to May 2015 [27] as a method of allowing their party base to elect non-binding guidelines on opinions on matters to be represented by the party. However, due to constraints of German law whatever has been decided online through LQFB was not binding (ibid.). Also, the party leadership actively refused to follow these decisions [39], which led to an erosion of relevance of the LD tool. According to the data presented by Kling \&al. [26] a sharp decline of user activity in their LQFB system could be observed towards the end of 2013. LQFB reached TRL 7-8.

The case of the German Pirate Party's use of LQFB is by far the most prominent and best studied case in which LD had been used in practice. It also is the only documented case of a LD system actually in use over a relevant period of time. Several scholarly publications have appeared describing the extent to which LD had been used by the German Pirate Party. Thus, Jabbusch's [24] graduate thesis [cf. 35] describes the story of the introduction of LD to the German Pirate Party; Kling \&al. [26] 
provide the only available data-based insights in voting behaviour within any LD system known; Korthagen \&al. [27] provide a description of and some reasons for the decline of LD in this party; Bullwinkel \& Probst [10] give insights into the implemented rules of voting and the dynamics of voting in LQFB as used by the German Pirate Party; Buck [9], Zolleis \&al. [53], and others [4, 31, 35,49 ] described and discussed the use of LD through LQFB in the German Pirate Party during its period of increased popularity and exposure to the public.

Another use of LQFB has been described in detail by De Cindio \& Stortone [15]. This was ProposteAmbrosoli2013, a LQFB pilot conducted in 2013 to promote a political candidate in occasion of the regional elections in the Italian region Lombardy. The pilot attracted 1.120 registrations, out of $46 \%$ never conducted any action, out of the remaining 609 nearly half conducted only one single action; only three users indicated that they had used the delegation feature of LQFB.

Further examples mentioned by De Cindio \& Stortone [15] of LQFB being used or piloted are Liquid Friesland [30], the civil society organisation "Slow Food Germany", the Italian Pirate Party, and several local groups of the Italian political movement "MoVimento 5 Stelle". Although the use of LQFB implies the possibility of delegating votes, for none of these cases reports of any actual use of vote delegation can be found. Two trials that took place in Italy in 2012 - one taking place in occasion of the 2012 Sicilian regional elections (attracted 315 registrations [15]), another as part of the TV show Servizio Pubblico, failed to reach levels of significance that would allow testing "the possibility for LQBF to enable purposeful and extensive initiatives of civic participation" (ibid.). Use of LD by Liquid Friesland, Slow Food Germany, and the German company Synaxon AG has been also mentioned by Ramos [43], who also fails to substantiate his claim.

\subsection{Civicracy}

Civicracy was a system developed by Madl \& Hainisch in 2012 at the Vienna University of Technology [21]. The system was born out of a research initiative and reached TRL 3-4.

The objectives of Civicracy differed slightly from those of Župa or those of LiquidFeedback: Civicracy aimed to use LD to constitute councils of representatives that would represent a larger group of members. The membership in these councils would fluctuate according to the principles of LD, thus the council members would not be fixed, but whoever would be holding an amount of delegated trust that would surpass a certain threshold would be member of the council. Furthermore, a dampening mechanism was built into the algorithm that would prevent impulsive action, thus making the "liquidity" of the delegations slightly more viscous.

The concept of the system was tested through simulations, and efforts were undertaken to convince the student union of the university to use the system for their operation. However, the student union showed no interest in using LD, so an experiment never materialized [35]. Another attempt was made to pilot the system at schools, but only about 20 students out of a required ca. 250 could be motivated to participate in the experiment [21].

\subsection{Google Votes}

From March 2012 to February 2015 Google ran a LD experiment, Google Votes, amongst its employees [22]. According to Hardt \& Lopes [22] the LD system was coupled to Google's internal social corporate network Google + , which was used for publication and dissemination of proposals. Google Votes attracted 15.000 employees to cast votes, out of which 3,6\% were delegated votes. 


\subsection{Sovereign}

Most recent to appear on the stage of LD systems was the Democracy Earth Foundation, which claims to have pioneered digital democracy by having authored "some of the most prominent open source democracy software as ranked by the GitHub community" [47]. Their claim is to have "founded the first digital political party in the Americas, the Partido de la Red (Peers Party) that ran for its first election in the city of Buenos Aires in 2013. In 2014 [they] shared [their] experience in TED Talks reaching over 1.2 million viewers. During 2015 and 2016, Silicon Valley's Y Combinator and Fast Forward founded [their] efforts to start the Democracy Earth Foundation”. (ibid.)

Democracy Earth Foundation is developing the system Sovereign [45], which according to Siri et al. [47] provides all features expected from a system that would enable LD. Thus, delegation of voting power, both topic-based ("tag limited delegation") as well as general, is possible, as are transitive delegations, and overriding of votes made by delegates on one's behalf; voting is possible both public as well as secret. Besides the LD module, a deliberation module, Agora, is available. Sovereign is a successor to DemocracyOS, "a simple direct democracy project [they] created in 2012" [47], which the Argentinian Partido de la Red aimed to use in an effort to attract votes as a so-called proxy party [33].

No data on any actual use of the software however is available so far. The organisation claims to have piloted the platform "in a digital plebiscite enacting a symbolic vote among the diaspora of $\sim 6$ million expatriate citizens" [47], however no information is available on the details of this pilot, such as e.g. the number of participants, the utilisation of LD features, the length of the pilot, etc.

\section{Varying perspectives on liquid democracy}

If a group wants to arrive at a collective decision or decides to empower somebody to act on behalf of the group, then it had traditionally two possibilities: it could elect some of its members as representatives to arrive at the decision on behalf of the group, or all of its members could arrive at the decision collectively by some form of voting. Both these traditional options involve some kind of expression of will by its members. This can be done through e.g. election, voting, or perhaps a mandate expressed in written form as for example power given to an attorney. Variations of these traditional methods are then applied in bodies of state governance (parliaments, city councils, elective assemblies, etc.), corporate governance (executive boards, shareholder meetings), or e.g. in situations of class action lawsuits.

With its characteristic liquidity LD goes beyond being an advanced voting mechanism. In their attempt towards establishing a thorough theory base for understanding LD, Reichert \& Panek [44] distinguish between the delegated voting feature, LD as an elaborate form of enabling participation of citizens in affairs of the state, and LD as a new form of a democracy in which democracy is seen a way of making public governance a responsibility of society, rather than a service provided by the state through its government. This section shall briefly outline this trinity of LD. 


\subsection{A voting mechanism}

Liquid democracy (LD) is an alternative way for groups to arrive at collective decisions. In contrast to voting, elections, or written delegation of power, which all involve a one-time expression of will by each member of the respective group, the LD concept enables each member of the group to delegate its power to another member (who can delegate it further), and withdraw it again at any time. Traditional voting is a single event: the group can vote on something, like for example what law will rule them, how their budget will be distributed, or who will represent them. LD on the other hand is a living network that describes the power relations within the group. Traditional voting is a process: when the process finishes, the group has arrived at a collective decision. Power distribution within LD on the other hand is a temporary state of the network -once a collective decision is to be made, those members that jointly hold enough power to decide on behalf of the group can make the decision virtually instantly. To this end, LD is first and foremost a novel mechanism.

The mechanism of LD described above is predestined for a novel form of voting. If thought of as a voting mechanism, LD is limited to delegating trust by electing representatives, or voting on preferences of a group on certain matters of public interest (such as for example policies or opinions). Accordingly, LD in terms of a voting mechanism can be easily applied to existing political systems, or for internal policy forming of political parties.

LD as a form of voting on non-binding policies has been implemented by the German Pirate Party [2, $24,26]$. LD as a way to vote for members of a council of representatives was the objective behind the system Civicracy [21]. The LD system Župa aimed to serve a student union to elect its officials in a LD way, and to vote on which projects to fund [41, 42]. Google Votes, an internal LD experiment of Google used LD to vote on the available food in their staff kitchens, logotypes of projects, and so on [22].

\subsection{An evolution of participatory democracy}

Political organisations that embraced LD perceived it predominantly as an evolved form of eparticipation. Thus, the German Pirate Party deployed LQFB as a tool to source the view of the party base on which directions the party should take [9, 10, 24, 27, 39]. LQFB has been designed as a LD tool for trust delegation and delegated voting, but not for discussions. The system Sovereign, on the other hand, which the Argentinian Partido de la Red aimed to rely on, offers also a debating component called Agora [47]. Other political parties such as the Italian Pirate Party, the MoVimento 5 Stelle movement, the ProposteAmbrosoli2013 candidacy, as well as regional initiatives such as Liquid Friesland, all aimed at offering citizens LD as an evolved form of e-participation.

A major reason for Blum \& Zuber's conclusion that LD is superior to representative democracy was that LD has "a greater capacity for mobilizing policy area expertise than its counterpart [in terms of that] it allows for policy area specific representation" [4]. This way, LD allows for instant fine-grained participation on matters that each citizen considers of interest to themselves, while exercising their interest in participating on shaping policy.

This view of LD being used for participation in policy-shaping has been adopted also by Caragiannis \& Micha [11], who see "the main idea of [LD being] to allow citizens to be involved actively in everyday decision making within society". From this perspective, they aim to assess "how effectively [LD] is in discovering the truth", whereby by truth they imply the existence of a ground truth / correct answer to any voting situation a community would face. Unlike Blum \& Zuber who consider LD 
being better suited for mobilizing expertise, Caragiannis \& Micha conclude that LD is "very ineffective in discovering the ground truth".

Also Reichert \& Panek [44] see LD as a warrant for the inclusion of stakeholders into the political discourse by allowing them to express their opinions in a way they would do in other participatory processes. As such, they consider that it is a main objective of LD to structure discourse on policy in a way to reduce the barriers to participation in such discourse as far as possible.

\subsection{A new form of democracy}

Some scholars use the term liquid democracy to stand more generally for a form of democracy. Ramos [43] for example emphasises that LD "represents the need for a new political contract that cannot simply be resolved within existing systems (representative, autocratic, or oligarchic)", pointing out that a transition to a LD as a new form of democracy would entail "political and social mobilisations and struggles that force a shift in the core rules of the game, much like the Magna Carta in England altered the landscape of social expectations in the exercise of power." (ibid.)

Blum \& Zuber [4] take the perspective of LD standing for a new form of democracy, when they compare LD to representative democracy and direct democracy. Comparing LD to representative democracy as the best systemic alternative, their conclusion is that LD "is more epistemically reliable and more egalitarian than representative democracy" (ibid.). Under such novel form of democracy, Blum \& Zuber see further research questions to be addressed in order to provide a full picture of the liquid democracy: "Should the executive consist of a president with an appointed cabinet? How exactly would a budgeting system work under liquid democracy? How should the agenda-setting process be structured? How should the reputation and ranking system be designed?" (ibid.)

Some of these questions posed by Blum \& Zuber have been addressed by Paulin. Budgeting in a liquid democracy is featured in the proposed "Quantum Budget", a model aimed to provide public funding by means of LD [38]. Some considerations how to empower executive roles in a liquid democracy have been made in the course of the LD systems Župa [41, 42] and Civicracy [21], as well as in more detail in Paulin's nonmediated governance concept [34, 36, 37, 39], in which he describes a liquid democracy in that executive roles as well as policies are assigned by means of LD.

\section{Summary}

This paper aimed to establish an overview of state of the art of research on and development towards liquid democracy (LD). To this end, the paper first defined LD based on the publications by Paulin [35] and Blum \& Zuber [4], then described the known technical systems based on the characteristics defined by von der Elbe [17], and finally discussed the trinity of LD by following the works of Reichert \& Panek [44] and others.

We found that while many organisations boast about using LD or intending to use LD, only few have actually used it, or developed systems capable of providing the functionality required for LD. Such LD-capable systems for which sufficient documentation exists are Votorola, Župa, LiquidFeedback, Google Votes, Civicracy, and Sovereign. Out of these systems, documentation exists only for LiquidFeedback and Google Votes that confirms that the systems were tested at least as pilots.

Having established a deep overview of published literature on LD, we found that LD is being a topic in two separate research communities: democracy researchers and researchers interested in artificial 
intelligence. The community of democracy researchers is interested in the developments of LD as a novel form of democracy, the artificial intelligence research community on the other hand is predominantly occupied with exploring LD as an advanced way of decision making.

The reviewed papers exposed a trinity of LD in terms of three different perspectives of the concept: From the first perspective, LD is an advanced way for communities to arrive at decisions beyond the traditional voting. From the second perspective, LD is a way of participation, in terms that it allows members of a society participate in matters of public interest, such as policy forming, budget allocation, and so on. From the third perspective, LD is a new form of democracy, in which public governance is a matter of the society, rather than a responsibility of the state [cf. 37].

\section{Bibliography}

[1] ANTONINI, A., et al., 2017. WeGovNow Deliverable D3.5 - Final release of WeGovNow platform prototype.

[2] BEHRENS, J., KISTNER, A., NITSCHE, A. and SWIERCZEK, B. 2014. The principles of LiquidFeedback. Interaktive Demokratie e.V.

[3] BLOEMBERGEN, D., GROSSI, D. and LACKNER, M., 2018. On Rational Delegations in Liquid Democracy. (Nov. 2018).

[4] BLUM, C. and ZUBER, C. I., 2016. Liquid Democracy: Potentials, Problems, and Perspectives: Liquid Democracy. Journal of Political Philosophy. 24, 2 (Jun. 2016), 162-182.

[5] BOELLA, G., TSAMPOULATIDIS, I., FRANCIS, L., GRASSI, E., KISTNER, A., NITSCHE, A., NOSKOV, A., SANASI, L., SAVOCA, A. and SCHIFANELLA, C., 2018. WeGovNow: A Map Based Platform to Engage the Local Civic Society. Companion of the The Web Conference 2018 on The Web Conference 2018 - WWW'18 (Lyon, France, 2018), 1215-1219.

[6] BOLDI, P., MONTI, C., SANTINI, M. and VIGNA, S., 2015. Liquid FM: Recommending Music through Viscous Democracy. arXiv:1503.08604v1. (Mar. 2015).

[7] BOYD, O .P., 2008. Differences in Grassroots Parties' e-Participation Systems. Örebro University.

[8] BRILL, M., 2018. Interactive Democracy. Proc. of the 17th International Conference on Autonomous Agents and Multiagent Systems (AAMAS 2018). (Stockholm, Sweden, Jul. 2018).

[9] BUCK, S., 2012. Liquid Democracy - eine Realisierung deliberativer Hoffnungen? Zum Selbstverständnis der Piratenpartei. Zeitschrift für Parlamentsfragen. 43, 3 (2012), 625-635.

[10] BULLWINKEL, B. and PROBST, L., 2014. Innerparteiliche Willensbildung und Entscheidungsprozesse durch digitale Partizipation. Ein Praxistest des Konzepts der Liquid Democracy. Zeitschrift für Parlamentsfragen. (2014), 382-401.

[11] CARAGIANNIS, I. and MICHA, E., 2019. A Contribution to the Critique of Liquid Democracy. Proceedings of the 28th International Joint Conference on Artificial Intelligence (2019). 
[12] CHRISTOFF, Z. and GROSSI, D., 2017. Binary Voting with Delegable Proxy: An Analysis of Liquid Democracy. Electronic Proceedings in Theoretical Computer Science. 251, (Jul. 2017), $134-150$.

[13] CHRISTOFF, Z. and GROSSI, D., 2018. Liquid Democracy: An Analysis in Binary Aggregation and Diffusion. arXiv:1612.08048v2. (Nov. 2018).

[14] Contributors to Votorola: http://reluk.ca/project/Votorola/contributors.xht. Accessed: 202001-01.

[15] DE CINDIO, F. and STORTONE, S., 2013. Experimenting LiquidFeedback for Online Deliberation in Civic Contexts. Electronic Participation. M.A. Wimmer, E. Tambouris, and A. Macintosh, eds. Springer Berlin Heidelberg. 147-158.

[16] DOWNING, A. and MOLLOY, B., 2013. Polly.

[17] VON DER ELBE, T., 2015. Software-Vergleich.

[18] FAN, X., LI, P., ZENG, Y. and ZHOU, X., 2019. Implement Liquid Democracy on Ethereum: A Fast Algorithm for Realtime Self-Tally Voting System. arXiv:1911.08774v1.

[19] FISCHER, A. E. ed., 2013. Schlussbericht der Enquete-Kommission "Internet und digitale Gesellschaft" [Final Report of the Commission of Enquiry "The Internet and the Digital Society"]. Deutscher Bundestag.

[20] GÖLZ, P., KAHNG, A., MACKENZIE, S. and PROCACCIA, A. D., 2018. The Fluid Mechanics of Liquid Democracy. arXiv:1808.01906v1. (Aug. 2018).

[21] HAINISCH, R. and PAULIN, A., 2016. Civicracy: Establishing a Competent and Responsible Council of Representatives Based on Liquid Democracy. Proceedings of the International Conference for E-Democracy and Open Government 2016 (Krems, Austria, May 2016), 1016.

[22] HARDT, S. and LOPES, L. C. R., 2015. Google Votes: A Liquid Democracy Experiment on a Corporate Social Network. Technical Disclosure Commons.

[23] HARRASS, S., 2015. Liquid Democracy im Feldversuch - Beteiligungsmöglichkeiten in der Enquete-Kommission "Internet und digitale Gesellschaft" des Deutschen Bundestages. Digitale Politikvermittlung. M. Friedrichsen and R.A. Kohn, eds. Springer Fachmedien Wiesbaden. 485-498.

[24] JABBUSCH, S., 2011. Liquid Democracy in der Piratenpartei - Eine neue Chance für innerparteiliche Demokratie im 21. Jahrhundert? [Liquid Democracy in the Pirate Party - A New Chance for Interparty-Democracy in the 21th Century?]. Universität Greifswald, Philosophische Fakultät.

[25] KAHNG, A., MACKENZIE, S. and PROCACCIA, A. D., 2018. Liquid Democracy: An Algorithmic Perspective. Proceedings of 32nd AAAI Conference on Artificial Intelligence (2018). 
[26] KLING, C. C., KUNEGIS, J., HARTMANN, H., STROHMAIER, M. and STAAB, S., 2015. Voting Behaviour and Power in Online Democracy: A Study of LiquidFeedback in Germany's Pirate Party. (2015).

[27] KORTHAGEN, I., LARSEN, C. F. and NIELSEN, R. Ø,. 2020. Non-binding DecisionMaking. European E-Democracy in Practice. L. Hennen, I. van Keulen, I. Korthagen, G. Aichholzer, R. Lindner, and R.Ø. Nielsen, eds. Springer International Publishing. 237-271.

[28] Liquid democracy uses blockchain to fix politics, and now you can vote for it: 2018. https://techcrunch.com/2018/02/24/liquid-democracy-uses-blockchain. Accessed: 2020-01-02.

[29] Liquid Democracy/Votorola: 2011. https://wiki.piratenpartei.de/Liquid_Democracy/Votorola. Accessed: 2020-01-01.

[30] Liquid Friesland, https://liquid-friesland.de. Accessed: 2020-01-06.

[31] LITVINENKO, A., 2012. Social Media and Perspectives of Liquid Democracy on the Example of Political Communication of the Pirate Party in Germany. Proceedings of the 12th European Conference on eGovernment (Barcelona, Jun. 2012), 403-408.

[32] Make Your Laws - Our Principles: 2015. https://web.archive.org/web/20150914233854/https:// www.makeyourlaws.org/principles. Accessed: 2020-01-02.

[33] MANCINI, P., 2015. Why it is Time to Redesign Our Political System. European View. 14, 1 (Jun. 2015), 69-75.

[34] PAUlin, A., 2019. Applied Nonmediated Governance: Common Scenarios. Smart City Governance. Elsevier. 251-270.

[35] PAULIN, A., 2019. Controlling Citizens or Controlling the State? Smart City Governance. Elsevier. 61-79.

[36] PAULIN, A., 2019. Model for Nonmediated Governance. Smart City Governance. Elsevier. $187-201$.

[37] PAULIN, A., 2019. Smart City Governance. Elsevier.

[38] PAULIN, A., 2019. The Quantum Budget vs. Participatory Budgeting. Proceedings of the 20th Annual International Conference on Digital Government Research (Dubai, United Arab Emirates, 2019), 154-158.

[39] PAULIN, A., 2014. Through Liquid Democracy to Sustainable Non-Bureaucratic Government - Harnessing the Power of ICTs for a novel form of Digital Government. eJournal of eDemocracy and Open Government. 6, 2 (2014), 216-230.

[40] PAULIN, A., 2019. WeGovNow - use of LiquidFeedback.

[41] PAULIN, A., 2010. Župa. University of Maribor. 
[42] PAULIN, A., 2010. Župa - Grassroots E-Democracy Revolution on the Web. Proceedings of the 4th International Conference on E-Democracy (Krems, 2010), 113-123.

[43] RAMOS, J., 2015. Liquid Democracy and the Futures of Governance. The Future Internet. J. Winter and R. Ono, eds. Springer International Publishing. 173-191.

[44] REICHERT, D. and PANEK, E., 2014. Alles ist im Fluss - die fließenden Ebenen einer Liquid Democracy. Internet und Partizipation. K. Voss, ed. Springer Fachmedien Wiesbaden. 299310.

[45] Sovereign: 2019. https://github.com/DemocracyEarth/sovereign.

[46] SWIERCZEK, B., 2014. Five Years of Liquid Democracy in Germany. The Liquid Democracy Journal. 1, 1 (Mar. 2014), 8-19.

[47] The Social Smart Contract: 2018. http://paper.democracy.earth/. Accessed: 2019-12-15.

[48] VELIKANOV, C., 2013. О демократии обыкновенной, прямой и электронной [On Traditional-, Direct- and e-Democracy]. Otchestvennye zapisky. 6, 57 (2013), 203-30.

[49] VOGELMANN, F., 2012. Flüssige Betriebssysteme. Liquid democracy als demokratische Machttechnologie. Aus Politik und Zeitgeschichte. 48, (2012).

[50] Votorola: 2014. http://reluk.ca/project/Votorola/home-2014.html. Accessed: 2020-01-01.

[51] Votorola - eine Softwareumgebung für Demokratie: 2009. http://webkompetenz.wikidot.com/ blog:64. Accessed: 2020-01-01.

[52] Votorola Shortlog: http://reluk.ca/var/repo/hg/votorola/shortlog. Accessed: 2020-01-01.

[53] ZOLlEIS, U., PROKOPF, S. and STRAUCH, F., 2010. Die Piratenpartei - Hype oder Herausforderung für die deutsche Parteienlandschaft [The Pirate Party - Hype or Challenge for the German Party Landscape]. Hanns-Seidel-Stiftung. 